\title{
Contar histórias - experiências e memórias
}

\section{Storytelling - experiences and memories}

Stela Nazareth Meneghel' 1 | $\mid$ stelameneghel@gmail.com

\section{RESUMO}

Introdução: Este texto é um relato de experiência que mescla memórias e histórias narradas em contextos de ensino, pesquisa e extensão no campo da saúde coletiva. O objetivo é mostrar a capacidade de histórias fazerem sentido aos interlocutores, despertando emoções e produzindo empatia.

Relato de experiência: Apresentam-se histórias escolhidas a partir de uma perspectiva interseccional, que inclui gênero, raça e classe social. Três subseções apresentam essas histórias: "Falando em gênero e a história do general”,"Haiti e a história da revolução negra” e “Como trabalhar com o povo?".

Discussão: A discussão rememora os contextos, os itinerários e as histórias contadas, assim como os efeitos produzidos pelas narrativas nos ouvintes.

Conclusão: Ressaltam-se a potência e os efeitos das histórias nos ouvintes e interlocutores.

Palavras-chave: Narrativas; Interseccionalidade; Educação em Saúde.

\section{ABSTRACT}

Introduction: This text is an experience report that combines memories and stories narrated in contexts of teaching, research and community outreach in the public health field. The objective is to show the ability of stories to make sense to interlocutors, arousing emotions and producing empathy.

Experience report: The stories presented have been chosen from an intersectional perspective, which includes gender, race and social class. The text was divided into three sections: talking about gender and the story of the General; Haiti and the history of the black revolution and how to work with the people?

Discussion: The discussion recalls the contexts, itineraries and stories told, as well as the effects produced by the narratives on listeners.

Conclusion: The power and effects of stories on listeners and interlocutors are highlighted.

Keywords: Narratives; Intersectionality; Health Education.

${ }^{1}$ Universidade Federal do Rio Grande do Sul, Porto Alegre, Rio Grande do Sul, Brasil.

Editora-chefe: Rosiane Viana Zuza Diniz.

Editor associado: Gustavo Antonio Raimondi.

Recebido em 26/10/21; Aceito em 05/01/22.

Avaliado pelo processo de double blind review. 


\section{INTRODUÇÃO}

O desejo de narrar, de contar histórias faz parte da natureza humana. Isso aparece nas cartas, nos diários, nas confissões íntimas e nos relatos pessoais. Walter Benjamin'1, em um texto clássico, mostra a potência das histórias e narrativas, ressaltando que a própria repetição delas produz nos ouvintes, além da fruição e do prazer despertados pelo relato em si, uma identificação com os temas tratados e a vontade de se tornar um narrador, um contador de histórias.

A escrita autobiográfica é uma forma de história autorreferente, um exercício de rememoração atravessado pela subjetividade do autor ${ }^{2}$, que pode dar lugar à voz dos silenciados da história ${ }^{3}$. A autoetnografia performática, por sua vez, é um relato biográfico, uma estratégia "método+lógica" e estética que problematiza os paradigmas epistemológicos hegemônicos eurocêntricos, brancos e patriarcais ${ }^{4}$.

Contar uma história para o outro, quer seja o estrangeiro, o membro de uma cultura diversa ou o(a) usuário(a) de um serviço de saúde é um exercício de imaginação, uma tentativa de mudar de lugar usando, inclusive, elementos autobiográficos, para estabelecer conexão, empatia, afecções.

Este relato de experiências vividas em espaços de pesquisa, ensino e extensão no campo da saúde coletiva objetiva mostrar a potência das histórias, escolhidas pelo(a) narrador(a) usando a intuição, o desejo de aproximação e a demonstração de respeito. Apresento então três experiências, nas quais escolhi uma história para contar a outra(s) pessoa(s), apostando que as narrativas fariam sentido para ela(s).

Neste relato de experiência, os cenários e as histórias foram marcados pela perspectiva de gênero, raça e classe social, adotando o conceito de interseccionalidade ${ }^{5}$, que opera com a interação entre os três eixos de subordinação e identifica a forma pela qual o racismo, o patriarcado, a opressão de classe criam e cimentam desigualdades.

\section{RELATO DE EXPERIÊNCIA E DISCUSSÃO}

\section{Falando em gênero e a história do general}

Em 2006, iniciamos uma pesquisa denominada Rotas Críticas de mulheres em situação de violência, inspirada em um estudo realizado na América Central coordenado pela pesquisadora Montserrat Sagot ${ }^{6}$. Interessados em discutir a pesquisa com sua idealizadora, organizamos um seminário que denominamos Rotas Críticas e convidamos a pesquisadora para vir ao Brasil'.

Começava um trabalho de cooperação entre os dois países, focado na violência contra a mulher e que envolveu um grande número de pesquisadores, estudantes de graduação e pós-graduação, trabalhadores sociais e de saúde, militantes feministas e de direitos humanos ${ }^{7,8}$.
As viagens são eventos promotores da paz entre os povos, proporcionam a formação de redes de estudos, de pesquisas e de amigos, podendo ser consideradas sementeiras de ideias. Nesse intercâmbio entre pesquisadores, sensibilizamo-nos com o tema dos femicídios, um problema bastante discutido na América Central e, na época, ainda pouco presente na produção acadêmica no Brasil. Motivados por essas discussões, iniciamos uma pesquisa sobre os femicídios que iria nos envolver por uma década ${ }^{9,10}$.

Em 2013, organizamos o 50 Seminário Internacional Rotas Críticas, pautado no tema dos femicídios, pensados como crimes de gênero. Queríamos convidar Rita Segato ${ }^{11,12}$, uma pesquisadora argentina, porém radicada no Brasil, e professora da Universidade de Brasília (UnB), que traz em suas escritas conceitos inovadores como o de femigenocídio, considerado crime de lesa-humanidade ou execuções de mulheres quando o Estado não lhes confere proteção. As vítimas de femigenocídios são mulheres pertencentes a grupos raciais, étnicos ou que por outras características são perseguidas e eliminadas. Femigenocídios estão acontecendo com mulheres indígenas na Amazônia do século XXI, assim como ocorreu na Bósnia, em uma Europa pretensamente civilizada do século $X X$, onde centenas de mulheres foram estupradas e mortas por membros de outro grupo étnico, para impor a supremacia racial que eles acreditavam possuir.

Em um primeiro contato, Rita recusou o convite. Estava em Jujuy, e, por acaso ou sorte, eu lia o livro Sobre heróis e tumbas, de Ernesto Sabato ${ }^{13}$, um drama no qual um dos eixos da narrativa é a morte do general Lavalle, herói da independência argentina, ocorrido na cidade de Jujuy.

Sabato começa a narrativa com a fuga do general Lavalle para o Norte do país, esperando contar com o apoio de soldados fiéis, porém os aliados o abandonam e ele precisa se refugiar em Jujuy, onde estava Rita no momento de nossa conversa.

No dia 9 de outubro de 1841, soldados federalistas encontram a casa onde se encontrava Lavalle e matam o general. Ao saberem de sua morte, os inimigos ordenam a busca do corpo para decapitá-lo e exibir sua cabeça em praça pública. Porém, oficiais leais conseguem fugir, ocultando o cadáver sob uma bandeira argentina e sob o poncho azul de um companheiro. Fogem em busca do território boliviano para que o corpo não fosse profanado. O relato de Sabato é envolvente, e não resisto e começo a contar para Rita essa história que não é minha, é patrimônio dos argentinos, é posse de Rita.

“Essa história me emociona”, disse Rita. “Estou aqui muito próxima da casa onde Lavalle foi morto."

Prosseguindo na subida, no ar cada vez mais rarefeito das montanhas, os fugitivos, às margens de um arroio, descarnam o corpo já apodrecido do general, enterram as carnes, mas colocam 
o coração em um frasco e acondicionam os ossos em um saco de couro. Assim, os restos de Lavalle são levados a Potosi, onde foram honrosamente recebidos pelo governo boliviano.

Após essa conversa, Rita veio ao Brasil e participou do seminário sobre femicídios. O passaporte foi a narrativa, o livro de Ernesto Sabato, a história do general Lavalle. O mérito foi da história que não era minha, era dela.

\section{Haiti e a história da revolução negra}

Em 2012, fui ao Haiti, onde estava sendo desenvolvida a Cooperação Brasil-Cuba-Haiti, e o grupo de trabalho coordenado pela Fundação Oswaldo Cruz (Fiocruz) havia solicitado uma proposta para a realização de atividades ligadas à epidemiologia e à vigilância epidemiológica ${ }^{14}$.

No Haiti, o nível central do Ministério de Saúde Pública e População (MSPP) possui profissionais qualificados, porém eles enfrentam problemas de comunicação entre os departamentos regionais e o nível central, assim como questões ligadas aos sistemas de informação, já que as inúmeras organizações não governamentais (ONGs) que operam no país não repassam os dados de atendimentos e outras informações aos serviços de saúde.

Os países imperialistas impuseram uma condição de subserviência ao Haiti desde a sua revolução. Uma revolução de escravos negros nunca aceita, nem mesmo pelos revolucionários franceses que deixaram de fora as mulheres e os escravos negros. As iniquidades em relação ao Haiti compreendem a indenização exorbitante que a França cobrou ao país, a ocupação pelos Estados Unidos no século $\mathrm{XX}$, o apoio à ditadura sanguinária de Duvalier e a gestão do país pelas Nações Unidas, a Missão das Nações Unidas para a Estabilização do Haiti (Mission des Nations Unies pour la Stabilisation en Haïti - Minustah), que propiciou a entrada da cólera e a explosão da epidemia.

Ainda procurando entender o cenário, propus um curso de Epidemiologia para os trabalhadores de saúde dos dez departamentos regionais de saúde do país. A ideia era melhorar os fluxos de comunicação entre os departamentos regionais e a coordenação central da vigilância epidemiológica no MSPP, estimular a produção de dados locais e discutir uma epidemiologia de serviços, articulada às políticas de saúde e usando metodologias de ensino críticas e pautadas em Paulo Freire ${ }^{15}$.

Começou então a tomar corpo um curso prático usando uma epidemiologia operacional como ferramenta para dar suporte aos serviços de saúde. A partir do texto "O que é essa tal epidemiologia?"16, a proposta foi sendo construída no coletivo, referenciando o Haiti por meio de dados epidemiológicos, demográficos e culturais.

E assim começou uma experiência ímpar e desafiadora. Foram oito módulos, incluindo epidemiologia básica, políticas de saúde, indicadores de saúde, doenças transmissíveis, gênero e violências, estudos analíticos e vigilância da saúde. Nesse trajeto de quatro anos, incluindo momentos presenciais e trabalhos de campo, produziram-se várias pesquisas: um estudo sobre subnotificação de óbitos, buscando mortes não declaradas em cemitérios ${ }^{17}$; uma avaliação da equidade de gênero na atenção em saúde ${ }^{18}$; e uma investigação epidemiológica sobre tétano acidental e neonatal, na qual foram realizadas visitas a maternidades e contataram-se e ouviram-se parteiras. Organizamos oficinas como ferramentas para serem usadas em educação permanente em saúde; houve sessões de cinema, disponibilizando filmes brasileiros para eles conhecerem o Brasil; e ministramos aulas de português.

Embora afirmássemos que não iríamos ensinar a história do Haiti para os haitianos, não conseguimos deixar de contar a eles a história da primeira revolução escrava vitoriosa. A história deles, que cada haitiano e cada haitiana sabe de cor.

Começamos com $O$ reino deste mundo, a história de uma insurreição de escravos em uma ilha imaginária, que remete ao Haiti. Usamos o realismo mágico de Alejo Carpentier ${ }^{19}$ para falar da figura mítica de Mackandal, o escravo que organizou uma das primeiras revoltas no Haiti e que permanece vivo como herói popular, cultuado como aquele que tem o poder de se metamorfosear em animal para fugir de seus inimigos, disfarçando-se em planta, borboleta, iguana, pássaro ou cobra.

Essa história dos haitianos que contamos para os haitianos aconteceu durante o curso de Epidemiologia, mas que não tratava apenas de epidemiologia, pois incluía a discussão sobre gênero, raça, religiosidade africana, determinação social das doenças, políticas de saúde, cultura, arte e afetos. "É a primeira vez que um curso é dado desta maneira aqui no Haiti, em que são apresentados filmes, histórias, se aprende português, somos consultados e as decisões são tomadas em conjunto", disse um dos 40 profissionais de saúde que participaram dessa experiência.

A pergunta que permanece é o quanto as histórias contribuíram para fomentar a empatia e a conexão, que se mantiveram e se fortaleceram no itinerário, apesar dos percalços da língua, apesar das intromissões e dos mal-entendidos que podem acontecer quando entramos na cultura do outro. Mesmo assim, acredito que as pessoas com as quais trabalhamos entenderam a intenção de que, ao contar outra vez a mítica história da rebelião negra, queríamos mostrar o nosso interesse, o nosso respeito e a nossa admiração ao Haiti e aos haitianos.

\section{Como trabalhar com o povo?}

Parafalar sobre as desigualdades de classe, o terceiro eixo de subordinação que faz parte da perspectiva interseccional, a questão que ainda nos desafia é: "Como trabalhar com 
o povo?". Para Paulo Freire ${ }^{20}$, a resposta está em respeitar no outro o direito de dizer a palavra. E reconhecer o direito de dizer a palavra significa ouvir o outro, falar com o outro e não para o outro. Então, buscando pensar freirianamente, perguntamos quais histórias podemos escolher para falar com as pessoas, histórias que possam reverberar nelas produzindo conexão e mudanças.

Olhamos ao redor e vemos recrudescer a intolerância, os preconceitos e o ódio. Observamos, estarrecidos, o aumento dos fundamentalismos religiosos que utilizam literalmente os textos sagrados, seja a Bíblia ou o Alcorão, sem desvinculá-los de uma realidade histórica que não existe mais e propugnando comportamentos conservadores e moralistas.

Então, nesse mundo tão desigual, em que proliferam tantas narrativas e versões díspares dos fatos, que histórias vamos contar AO outro, como nos ensinou Paulo Freire ${ }^{20}$ ? Que histórias estão a serviço do povo e que histórias são artifícios para enganar as pessoas? Que histórias são potentes para produzir consciência crítica e rompimento com a subordinação e a opressão?

Entendemos que o contar histórias pode funcionar como um antídoto à tristeza, à angústia e ao medo, contribuindo para a aceitação de perdas, de doenças e mesmo da morte. Isso foi observado em encontros de extensão, nos quais os estudantes, ao falarem sobre as angústias e os medos despertados durante a epidemia da coronavirus disease 2019 (Covid-19), expressaram o desejo de contar histórias em textos e relatos autobiográficos organizados em um (anti)manual ${ }^{21}$.

Outras experiências em que houve espaço para contar histórias realizadas no trajeto de pesquisas e de projetos de extensão na área da saúde coletiva propiciaram a emergência dos mais diversos tipos de narrativas. Excertos de autores consagrados, histórias populares, textos e poesias inventados pelos membros e pelas membras dos grupos, fábulas e relatos do folclore universal, contos dos povos autóctones e da cultura afro-brasileira e, até mesmo, histórias bíblicas ${ }^{22}$.

O uso das histórias bíblicas pode constituir um mecanismo ideológico de difusão de valores conservadores, chancelando comportamentos moralistas e conformistas. Contudo, a linguagem poética e polissêmica das parábolas e mensagens extraídas da Bíblia é de fácil entendimento e do gosto popular. Um exemplo é a história de José em que Thomas Mann ${ }^{23}$, ao recontar a narrativa já conhecida na cultura e difundida pelas religiões judaico-cristãs, atualiza e humaniza o relato bíblico, colocando-o no mundo do cotidiano.

Ao falar de histórias bíblicas, rememoro uma atividade de acolhimento em um grupo de mulheres, que fazia parte de uma pesquisa sobre violência intrafamiliar e de gênero, em que a história que emergiu foi a parábola do Filho Pródigo, contada a mães encaminhadas pelo Conselho Tutelar, cujos filhos adolescentes haviam fugido de casa ${ }^{24}$. Era o primeiro encontro, momento crucial para a adesão das pessoas ao grupo. Uma das mulheres levantou-se e começou a contar a sua história. Há algo de trágico e doloroso quando uma pessoa faz um relato público de uma infração de direitos, de uma perda ou de uma violência ${ }^{25}$. A mulher narrou o desespero pelo filho que saiu de casa e ficou um ano desaparecido. Contou do itinerário percorrido, das noites sem dormir, da busca em todos os lugares possíveis, culminando com a ida à polícia e ao Conselho Tutelar. E finalmente falou que não voltaria ao grupo, não precisava mais, pois o filho voltara para a casa naquela mesma semana e ela estava feliz.

Algumas mães enxugavam as lágrimas discretamente, seus filhos não haviam voltado para casa. O que se poderia dizer àquelas mulheres? O que pode trazer consolo ao inconsolável? A ideia que brotou foi a parábola do Filho Pródigo, uma história de mil anos que assegura que o filho parte, mas um dia ele volta. E aquelas mães cujos filhos sumiram de casa ouviram emocionadas a história, certamente já conhecida por todas, mas que acenava para o consolo e para a esperança do regresso. E a mulher que havia dito "não voltarei ao grupo, não preciso mais", aquela que havia dado o depoimento motivando o relato da história bíblica, esteve presente em todo o itinerário grupal, funcionando como coterapeuta, partilhando no coletivo a sua voz, a sua experiência e a sua vontade de colaborar.

\section{CONSIDERAÇÕES FINAIS}

Talvez se possa dizer que escolher uma história para contar a outro, de modo similar à autoetnografia, seja um processo atravessado por subjetividades, capaz de conectar pessoas e produzir emancipação, mas também de promover rupturas, desafiar discursos hegemônicos e visibilizar mecanismos de opressão articulados biográfica, política e socialmente ${ }^{4}$.

Mesmo potentes e capazes de produzir identificações, insights e alternativas para situações de sofrimento, angústia ou violência, as narrativas nem sempre produzem efeito nos ouvintes. Isso acontece quando a escolha das histórias não corresponde à cultura do grupo, podendo despertar estranheza ou incompreensão ou quando as pessoas estão imersas em processos de luto ou de sofrimento psíquico intenso. Enfim, quando as histórias que contamos não conseguem fazer com os ouvintes se sintam identificados com elas e, portanto, "não há liga", como diz o povo.

Então, as histórias podem nos ajudar a "falar com o povo", porém nem sempre. Quando se escolhe uma história para contar, é preciso colocar-se na posição do ouvinte, e, como afirmou Paulo Freire ${ }^{20}$, devemos ouvir o outro e falar com ele e não para ele. E por fim, como apontou Walter Benjamim', o narrador, 
quando conta uma história, não deve ter a pretensão de resolver a vida daquele que ouve ou de prescrever uma conduta a ser seguida, mas, apenas, de agregar outras possibilidades a uma narrativa em aberto, a história daquela vida.

\section{CONTRIBUIÇÃO DA AUTORA}

A autora participou efetivamente da conceituação do projeto, da curadoria de dados, da análise formal, da investigação, da metodologia, da redação original e da revisão do artigo.

\section{CONFLITO DE INTERESSES}

Declaro não haver conflito de interesses.

\section{FINANCIAMENTO}

Declaro não haver financiamento.

\section{REFERÊNCIAS}

1. Benjamin W. Magia e técnica, arte e política: ensaios sobre literatura e história da cultura. São Paulo: Brasiliense; 1987. (Série Obras escolhidas, v. 1).

2. Abrahão MHMB. A aventura (auto)biográfica. Porto Alegre: EDIPUCRS; 2004.

3. Oliveira MG. Os sons do silêncio: interpelações feministas decoloniais à História da historiografia. Hist Historiogr. 2018;11(28):104-40.

4. Raimondi GA, Moreira C, Brilhante AV, Barros NF. A autoetnografia performática e a pesquisa qualitativa na saúde coletiva: (des)encontros método+lógicos. Cad Saude Publica. 2020; 36(12):e00095320.

5. Crenshaw K. Documento para o encontro de especialistas em aspectos da discriminação racial relativa à gênero. Rev Est Fem. 2002; ano 10:171-88.

6. Sagot M. Ruta crítica de las mujeres afectadas por la violencia intrafamiliar en América Latina: estudio de caso de diez países. Washington: Organización Panamericana de la Salud; 2000.

7. Meneghel SN, organizadora. Rotas críticas de mulheres em situação de violência. São Leopoldo: Editora Unisinos; 2007.

8. Meneghel SN, Maciazeki RC, Sagot M, Lozano BR, Bairros FS, Martins AB. Mujeres conversando con mujeres: un encuentro en el seminario Rutas Críticas 8. Salud Colect. 2019; 15:e1871.
9. Meneghel SN, Hirakata VN. Femicídios: assassinatos de mulheres no Brasil. Rev Saude Publica. 2011;45(3):564-74.

10. Meneghel SN, Margarites AF. Femicídios em Porto Alegre, RS: iniquidades de gênero ao morrer. Cad Saude Publica. 2017;33(12):e00168516.

11. Segato RL. Gênero e colonialidade: em busca de chaves de leitura e de um vocabulário estratégico descolonial. e-cadernos CES. 2012;18:106-31.

12. Segato RL. Las nuevas formas de la guerra y el cuerpo de las mujeres. Soc Estado. 2014; 29(2):341-71.

13. Sabato E. Sobre heróis e tumbas. Rio de Janeiro: Companhia das Letras; 2002

14. Meneghel SN, Schramm JM, Ferla AA, Ceccim RB. Training in epidemiology and health surveillance: Tripartite Cooperation between Brazil, Cuba, and Haiti. Hist Cienc Saude Manguinhos. 2016;23(2):495-508.

15. Freire P. Pedagogia da autonomia. São Paulo: Terra e Paz; 1996.

16. Meneghel SN. Epidemiologia: exercícios indisciplinados. Porto Alegre: Tomo Editorial, Rede Unida; 2015.

17. Meneghel SN, Schramm JA, Ferla AA, Philogène MJ, Saint-Val ME, Manice $C$, et al. Recherche sur les sous-declarations de décés, Saint Marc, Haiti, 2012. Ciênc Saúde Colet. 2014;19(11):4505-12.

18. Jaques N, Meneghel SN, Danilevicz, IM, Schramm JMA, Ferla AA. Equidade de gênero na atenção à saúde de mulheres no Haiti. Rev Panam Salud Publica. 2017;41:e34.

19. Carpentier A. O reino deste mundo. Rio de Janeiro: Record; 1985.

20. Freire P. Pacientes impacientes. In: Ministério da Saúde. Caderno de Educação Popular. Brasília: Ministério da Saúde; 2007. p. 32-45.

21. Meneghel SN, Gomes AL, Meneghetti B, Silva KS, Ribeiro RHF, organizadores. Antimanual para enfrentar a Covid 19: falando de medo, angústias e violências. Porto Alegre: Rede Unida; 2020.

22. Meneghel SN. Contadores de histórias: uma experiência de grupos de mulheres. Athenea Digital. 2014;14(4):113-28

23. Mann T. José e seus irmãos: as histórias de Jacó e o jovem José. José no Egito. José, o provedor. Rio de Janeiro: Nova Fronteira; 2000.

24. Meneghel SN, Armani T, Severino R, Garcia AM, Mafioleti B, Fochi E, et al Cotidiano violento - oficinas de promoção em saúde mental em Porto Alegre. Ciênc Saúde Colet. 2000;5 (1):193- 203.

25. Boltanski L. El amor y la justicia como competencias. Tres ensayos de sociología de la acción. Buenos Aires: Amorrortu; 2000.

\section{ERRATA}

Na página 2, onde se lê:

[...] foi validado no Japão, em $2011^{10}$ there is no standardized tool for its measurement. The authors sought to verify the validity, reliability, and generalizability of the Professionalism Mini-Evaluation Exercise (P-MEX, na Finlândia, em 2015 ${ }^{11}$, e no Irã, em 201912, mostrando evidências de validade, confiabilidade e reprodutibilidade dos resultados nesses países.

O Brasil ainda tem poucos estudos que abordam métodos de avaliação de profissionalismo médico ${ }^{13}$. Na literatura em língua portuguesa, não foi identificado nenhum instrumento que avalie o profissionalismo durante a formação médica. O contrato social que sustenta o profissionalismo médico pode ser enfraquecido quando importamos apenas documentos e instrumentos de avaliação de outros países. O que temos no Brasil referente ao tema é baseado, principalmente, no ensino e na avaliação do profissionalismo a partir de matrizes internacionais ${ }^{14}$ and has been recognized as a skill that should be developed by all health professionals. Objective: The aim of the present study was to assess professionalism among graduates of health-related courses on a worldwide scale. Methods: Systematic review following the recommendations of the Preferred Reporting Items for Systematic Reviews and Meta-Analyses (PRISMA. 
Para possibilitar a padronização da avaliação do profissionalismo de médicos residentes no cenário brasileiro e o acompanhamento longitudinal ao longo da sua formação profissional, faz-se necessária a utilização de um instrumento adaptado para uso no país. O objetivo do presente trabalho é a tradução e a adaptação transcultural para a língua portuguesa do instrumento P-MEX, já utilizado em outros países para avaliação do profissionalismo.

\section{MÉTODOS}

Trata-se de uma pesquisa metodológica de tradução e adaptação transcultural do instrumento de avaliação de profissionalismo P-MEX que foi realizada no período de julho de 2019 a agosto de 2020. O P-MEX consta de 21 itens que contemplam quatro domínios, a saber: habilidades de relacionamento médico-paciente, habilidades reflexivas, gestão do tempo e habilidades de relacionamento interprofissional9the Professionalism Mini-Evaluation Exercise (P-MEX. Embora uma versão mais longa de 24 itens tenha sido usada nos estudos de validação do P-MEX no Canadá e no Japão, os autores do instrumento apoiaram e orientaram o uso da versão de 21 itens.

\section{Considera-se:}

[...] foi validado no Japão, em $2011^{10}$, na Finlândia, em 2015 ${ }^{11}$, e no Irã, em 2019 ${ }^{12}$, mostrando evidências de validade, confiabilidade e reprodutibilidade dos resultados nesses países.

O Brasil ainda tem poucos estudos que abordam métodos de avaliação de profissionalismo médico ${ }^{13}$. Na literatura em língua portuguesa, não foi identificado nenhum instrumento que avalie o profissionalismo durante a formação médica. O contrato social que sustenta o profissionalismo médico pode ser enfraquecido quando importamos apenas documentos e instrumentos de avaliação de outros países. O que temos no Brasil referente ao tema é baseado, principalmente, no ensino e na avaliação do profissionalismo a partir de matrizes internacionais ${ }^{14}$.

Para possibilitar a padronização da avaliação do profissionalismo de médicos residentes no cenário brasileiro e o acompanhamento longitudinal ao longo da sua formação profissional, faz-se necessária a utilização de um instrumento adaptado para uso no país. O objetivo do presente trabalho é a tradução e a adaptação transcultural para a língua portuguesa do instrumento P-MEX, já utilizado em outros países para avaliação do profissionalismo.

\section{MÉTODOS}

Trata-se de uma pesquisa metodológica de tradução e adaptação transcultural do instrumento de avaliação de profissionalismo P-MEX que foi realizada no período de julho de 2019 a agosto de 2020. O P-MEX consta de 21 itens que contemplam quatro domínios, a saber: habilidades de relacionamento médico-paciente, habilidades reflexivas, gestão do tempo e habilidades de relacionamento interprofissional ${ }^{9}$. Embora uma versão mais longa de 24 itens tenha sido usada nos estudos de validação do P-MEX no Canadá e no Japão, os autores do instrumento apoiaram e orientaram o uso da versão de 21 itens.

\section{Na página 6, onde se lê:}

A aplicação desse instrumento fornecerá contribuições na avaliação sobre o nível de profissionalismo do médico residente, permitindo analisar adequadamente seu desempenho profissional durante toda a sua formação e, quiçá, possibilitando interferências nas discrepâncias observadas pelos preceptores ${ }^{21,22}$ mandated by accrediting bodies. Responding to a call for comprehensive research on remediation of student professionalism lapses, the authors explored current medical school policies and practices. Method In 2012-2013, key administrators at U.S. and Canadian medical schools accredited by the Liaison Committee on Medical Education were interviewed via telephone or e-mail. The structured interview questionnaire contained open-ended and closed questions about practices for monitoring student professionalism, strategies for remediating lapses, and strengths and limitations of current systems. The authors employed a mixed-methods approach, using descriptive statistics and qualitative analysis based on grounded theory.

\section{Considera-se:}

A aplicação desse instrumento fornecerá contribuições na avaliação sobre o nível de profissionalismo do médico 
residente, permitindo analisar adequadamente seu desempenho profissional durante toda a sua formação e, quiçá, possibilitando interferências nas discrepâncias observadas pelos preceptores ${ }^{21,22}$.

Na página 7, onde se lê:

Results Ninety-three $(60.8 \%$. Dessa forma, o instrumento poderá ser utilizado como objeto de melhoria do profissionalismo ${ }^{23}$. Além disso, trata-se de uma ferramenta de avaliação direta, rápida e de fácil execução, cuja aplicação, pode ser estendida ao estudante de Medicina.

\section{Considera-se:}

Dessa forma, o instrumento poderá ser utilizado como objeto de melhoria do profissionalismo ${ }^{23}$. Além disso, trata-se de uma ferramenta de avaliação direta, rápida e de fácil execução, cuja aplicação, pode ser estendida ao estudante de Medicina.

Revista Brasileira de Educação Médica, 46(1): e062, 2022. 